\title{
CICLOS DA SULANCA: TEMPORALIDADES E TERRITORIALIDADES DO TRABALHO COM VESTUÁRIO EM CARUARU- PE-BR
}

Wecisley Ribeiro do Espírito Santo ${ }^{1}$

\section{Introdução.}

Este artigo apresenta um fragmento do universo social de trabalhadoras e trabalhadores do vestuário de Caruaru (município do estado de Pernambuco, Brasil), recortado a partir de tempos e espaços que lhes são característicos. Trata-se de pensar de modo articulado duas escalas distintas de temporalização dos ciclos da sulanca ${ }^{2}$. Este é um termo nativo abrangente, que se refere à produção e circulação de roupas e outros objetos (bolsas de retalho, lençóis para camas, fronhas, travesseiros, arranjos de flores e uma miríade de outros objetos artesanais, confeccionados a partir do reaproveitamento das sobras da matéria prima do vestuário), no Agreste de Pernambuco. Pretende-se discutir três aspectos do mundo dos trabalhadores deste setor. O primeiro deles refere-se às categorias sulanca e sulanqueiros e às esferas sociais nas quais elas são enunciadas. Nesse sentido, apresento nesta introdução algumas informações gerais como meio de fornecer um contexto para as reflexões mais específicas que se seguem. O segundo aspecto refere-se ao que poderíamos chamar de "ciclos temporais da sulanca", a saber, suas temporalidades específicas. Por fim, apresento as territorialidades da sulanca (ou seus ciclos territoriais), a partir do exemplo de um bairro majoritariamente habitado por trabalhadores do vestuário domiciliares - o bairro do Salgado - e de suas conexões com o espaço da feira da sulanca.

Caruaru - que dista 130 km de Recife - possui um território com cerca de 921 quilômetros quadrados onde, segundo o censo realizado pelo IBGE, em 2010, habitam aproximadamente 314.951 pessoas. Pode-se a isso somar uma população flutuante que reside intermitentemente na cidade perfazendo algo em torno de 500.000 habitantes.

\footnotetext{
${ }^{1}$ Universidade do Estado do Rio de Janeiro, Brasil. Email: wecisley@yahoo.com.br ORCID id: https://orcid.org/0000-0002-9307-9410

${ }^{2} \mathrm{O}$ formato itálico é empregado para enfatizar termos e expressões nativas, sobretudo quando aparecem pela primeira vez, mas também quando vale à pena enfatizar seu conteúdo êmico. Idiomas estrangeiros também são grafados em itálico. O leitor saberá, no entanto, diferenciar pelo contexto um e outro caso.
} 
São, por exemplo, estudantes de cidades adjacentes - e até mesmo de Recife, de Campina Grande, além de outros locais da Paraíba - que vêm para este município do agreste pernambucano atraídos pelos campi da Universidade Federal de Pernambuco, do Centro Federal de Educação Tecnológica ou por outras universidades privadas ali existentes. Além disso, já que as feiras da sulanca de Caruaru, Toritama e Santa Cruz do Capibaribe (as três principais cidades do chamado polo de vestuário do agreste pernambucano) realizam-se em dias diferentes, muitos sacoleiros que vêm para a região em busca das mercadorias que lhes são características tendem a permanecer parte da semana hospedados em uma destas três cidades. Seu José Mário ${ }^{3}$ (pai da família que me hospedou, no bairro do Salgado e, sem dúvida, minha via de acesso privilegiada ao mundo da sulanca) certa vez me disse o seguinte a este respeito: "muita gente vem pra Caruaru porque o dinheiro da feira da sulanca vem de fora e fica aqui”.

Esta incidência de um grande volume de pessoas que chegam a Caruaru vem reforçar um tema nativo dos mais difundidos entre os diversos grupos sociais e coletivos com os quais mantive contato no município - a saber, a centralidade geográfica da cidade, no contexto do estado de Pernambuco, especificamente, e do Nordeste brasileiro, em geral. Esta centralidade é interpretada, em termos êmicos, como uma das razões pelas quais a cidade têm conhecido prodigioso desenvolvimento econômico com base na feira da sulanca. A própria Feira de Caruaru (da qual a feira da sulanca constitui apenas um segmento, embora o mais importante do ponto de vista econômico) é com frequência mencionada como alguma coisa que precede a cidade mesma, tendo sido engendrada com base no intenso trânsito de pessoas (provenientes da zona da mata, do sertão, do norte, do sul) por este lugar central.

No que se refere às condições climáticas e geomorfológicas Caruaru constitui um município pertencente ao semiárido nordestino, com clima seco, chuvas escassas e mal distribuídas, com maior incidência durante os meses de abril a junho. O clima varia entre $25^{\circ}$ a $35^{\circ}$ no verão e $15^{\circ}$ a $20^{\circ}$ no inverno. Por ser uma região sujeita a estiagens, a cidade se insere no Polígono das Secas, com índice pluviométrico anual de 500mm. O município pertence ainda à mesorregião do agreste pernambucano, sendo também parte constitutiva da microrregião denominada vale do Ipojuca (IBGE, 2010). Em 2006 o IBGE, por meio de um senso agropecuário, registrou uma "população rural" constituída por 36.853 pessoas - o que demonstra, por efeito de contraste, a proeminência do meio

\footnotetext{
${ }^{3}$ Todos os nomes de informantes citados são verdadeiros.
} 
urbano. Apenas para tomar o exemplo de uma cultura agrícola importante para a região, no mesmo ano Caruaru produziu aproximadamente 1.376 toneladas de macaxeira (ou mandioca).

$\mathrm{Na}$ esfera urbana, por seu turno, o setor mais importante da economia caruaruense é aquele ligado à sulanca. No âmbito do setor de produção e comercialização de peças de vestuário da região do agreste pernambucano, sulanca constitui um termo de significado mais ou menos abrangente segundo o contexto de enunciação. Referindo-se inicialmente ao tecido que serviu, por algum tempo, como matéria-prima principal da produção de vestuário, ele passou a designar também o produto acabado, o local onde as peças são comercializadas (feira da sulanca), como também o conjunto das unidades produtivas da região - também chamado de polo de confecções do Agreste de Pernambuco ou polo da sulanca. É preciso também notar que outros termos foram aos poucos derivando do primeiro. Este é o caso de sulanqueiro, que se refere simultaneamente ao dono de um fabrico - ao qual se contrapõe o dono de confecção, que não é sulanqueiro, mas empreendedor -; a um costureiro de vestuário seja ele empregado de outrem ou produtor por conta própria (ou, como meus interlocutores agrestinos costumam dizer, produtor com a família e para a família ${ }^{4}$ )-; a um comerciante da sulanca na feira; e a um sacoleiro, que vem na maioria das vezes de outros estados do país, ou mesmo de outros países, adquirir as peças de vestuário para revendê-las em sua própria região. Os empreendedores, por seu turno, se definem em contraposição às características fundamentais dos sulanqueiros. Estes últimos, ao contrário, podem se conceber também como empreendedores e, por vezes, simultaneamente como empreendedores-sulanqueiros. Daí que o significado específico

\footnotetext{
${ }^{4}$ Não disponho aqui do espaço necessário para desenvolver as implicações desta organização sui generis dos fabricos a partir do trabalho com a família e para a família. Contento-me, portanto, em sugerir apenas que estes arranjos produtivos fundamentam-se em uma oposição entre os da familia e os de fora. O pertencimento ao primeiro grupo frequentemente constitui condição de possibilidade para se trabalhar junto, enquanto os de fora são sempre potencialmente perigosos, porquanto pouco inspiradores de confiança. Daí a preferência pelo trabalho com a família. A segunda expressão - qual seja, o trabalho para a família - significa, como ouvi de muitos informantes, que os rendimentos financeiros proporcionados pelo trabalho devem sempre deixar alguma coisa de valor para a família. O dinheiro em si, sendo efêmero, não possui tanto valor senão no momento em que é convertido em um patrimônio perene para a família - um automóvel, um terreno, uma casa, etc. Estes dois princípios organizadores do trabalho nos fabricos constituem também os aspectos que os distinguem da lógica industrial clássica, segundo a qual a expansão do capital pressupõe a contratação impessoal de profissionais especializados de fora, e os lucros da empresa devem reinserir-se ad infinitum no circuito do mercado, permanecendo em circulação, ao contrário de sua conversão em um patrimônio estável. Sobre este último ponto ver Brenner (1998). Cf. Espírito Santo (2015) para um relato pormenorizado a este respeito.
} 
destas e de outras categorias nativas só possa ser capturado contextualmente. Para fazer jus à polissemia destas categorias é necessário imaginar uma forma de "pluralização nominalista das categorias" (Goldman, 2006:168) que seja capaz de organizar um relato de suas variações de sentido, em cada caso específico.

A versão mais evocada pela população local para dar conta das origens da palavra sulanca é uma junção de sul (referido à região sudeste do país, supostamente o local de onde vieram os primeiros retalhos que serviram de base para a costura de roupas) e helanca (tecido de que os retalhos eram constituídos). Outra explicação variante é aquela segundo a qual o termo seria uma simplificação da expressão sucata de helanca, referindo-se à antiga acepção pejorativa do termo, hoje bastante enfraquecida - embora não abandonada, sobretudo por parte dos empreendedores para os quais esta palavra estigmatiza os produtos de suas confecções. Há, por outro lado, aqueles que sustentam que o termo constitui uma marca da identidade dos produtos de vestuário agrestinos; alguns deles (creio que poucos) defendem o registro de uma patente da marca. Muito expressivo a este respeito é a fala de um de meus informantes em Caruaru chamado Clelson: "Moda tem em todo lugar, sulanca só tem aqui”.

Segundo um "Estudo de Caracterização Econômica" do polo da sulanca realizado, em 2003, pela Universidade Federal de Pernambuco, Caruaru, Santa Cruz do Capibaribe e Toritama possuíam, naquele ano, cerca de 14.000 unidades produtivas de vestuário, das quais apenas $8 \%$ eram formais, com CNPJ, registro profissional de seus trabalhadores, etc. Mensalmente, no mesmo período, este polo de confecções movimentava cerca de 1,6 bilhões de reais, sendo também detentor de $14 \%$ de toda a produção nacional de roupas e $73 \%$ do volume produtivo de Pernambuco. Embora (na ausência de um estudo similar e, sobretudo em decorrência da predominância da informalidade no setor) seja difícil registrar os números atuais estima-se que estas cifras sejam bem maiores. Segundo o IBGE, o PIB per capita de Caruaru cresceu de $\mathrm{R} \$ 10.850,51$ para $\mathrm{R} \$ 17.880,19$ entre 2010 e 2016. O acesso em grande medida democrático a meios de comercialização da produção familiar, objetivados nos circuitos de feiras livres da região, constitui uma das mais importantes condições de possibilidade deste desenvolvimento.

Os múltiplos arranjos produtivos, e seus correspondentes grupos sociais, construídos, na maioria das vezes, pelo trabalho articulado de familiares e vizinhos, que um observador testemunha em meio a este contexto, possuem também temporalidades 
próprias. As próximas duas seções deste texto tentam apresentá-las. Por seu turno, a quarta parte se ocupa das territorialidades também específicas deste universo e que se relacionam com aquelas escalas de temporalização.

\section{O tempo das vacas magras $e$ o tempo das vacas gordas: primeiro nível de temporalização da sulanca}

Tive a oportunidade de conversar uma tarde inteira com um sulanqueiro do qual fui vizinho, no bairro do Salgado, chamado José Sinovaldo. Em determinado momento, quando falávamos de sua jornada diária de trabalho ele me disse que isso variava muito de acordo com a época do ano. "Tem o tempo das vacas gordas e o tempo das vacas magras. No meio e no fim da festa de São João é melhor, na véspera do natal também" - afirmou Sinovaldo, evocando um tema que perpassa as falas e depoimentos de meus interlocutores de Caruaru, como também de alguns trabalhadores que entrevistei em Santa Cruz do Capibaribe e em Toritama. Com efeito, meus interlocutores enfatizam certa instabilidade do volume de vendas na feira da sulanca que tende a corresponder tanto a um calendário dos eventos importantes, na cidade, quanto às datas nacionais que movimentam o consumo na feira e alimentam trocas de presentes - tais como natal, dia das mães, etc. Por outro lado, nos interstícios destas ocasiões, o movimento de sacoleiros que vêm para o agreste pernambucano à procura da sulanca $\mathrm{e}$ de outras mercadorias que a acompanham tende a reduzir.

Esta intermitência que marca o volume de vendas, na feira, incide também sobre o ritmo da produção de vestuário nas confecções, lavanderias, fabricos, oficinas domésticas e demais unidades de produção da região. Por conseguinte, o trabalho dos costureiros e costureiras, a intensidade da exploração e da autoexploração de sua força de trabalho, acompanham este ciclo temporal, expresso aqui pelo que denomino o primeiro nível (ou escala) de temporalidade da sulanca. Diano, um grande colaborador desta investigação que trabalha em um fabrico familiar vizinho de Sinovaldo, também destaca estas variações temporais em seu trabalho:

Às vezes melhora um pouquinho. Quando a feira melhora a gente trabalha de dia e de noite. Durante o São João, lá pelo dia 15 de junho e no final da festa é assim. No fim do ano também é assim. A gente trabalha dia e noite. Vende pro Brasil todo. A feira e o Alto do Moura vendem [artesanato, no caso do Alto do Moura] muito no São João. (Diano, sulanqueiro dono de um fabrico familiar). 
Há diferenças na maneira pela qual os sulanqueiros se referem a esta instabilidade anual da produção e comercialização de suas mercadorias - o tempo das vacas magras e o tempo das vacas gordas, diz José Sinovaldo; Tempo bom e tempo fraco, conforme Diano; Tem época que sai muito e época que sai pouco, etc. Também uma frase de dona Eugênia, esposa de seu José Mário e interlocutora arguta da pesquisa, fornece uma imagem interessante do tempo das vacas gordas: "São João é a feira que quem entra não consegue sair e quem tá fora não consegue entrar. Aí fíca helicóptero sobrevoando a feira pra mostrar quanto de gente que tem", referindo-se com isso a tomadas jornalísticas aéreas.

Esta temporalização do trabalho orienta os sulanqueiros não apenas em seu planejamento e cálculo sobre o volume de trabalho necessário em cada período da escala (e sobre a infraestrutura necessária, tal como a necessidade de alugar máquinas de costura adicionais no tempo das vacas gordas), senão também sobre as necessidades de variação dos produtos, dos modelos de peças de vestuário, do emprego de novos tecidos, e do recurso a outras práticas econômicas e ofícios profissionais. Dona Jacira, faccionista domiciliar - isto é, produtora parcelar de peças de vestuário cuja produção integral se divide entre diversos domicílios, as casas do bairro constituindo, por assim dizer, uma linha de montagem - que trabalha para cerca de quatro clientes, isto é fabricos, facções ou confecções (entre os quais se estabelecem contratos para cooperação produtiva denominados facção) ilustra a intensidade do trabalho no tempo das vacas gordas, bem como a necessidade de alugar máquinas quando a produção aumenta muito:

Você veja que esse ano eu não consegui parar nem um dia. Não para de chegar serviço. Eu trabalho com estas três máquinas aqui, que são minhas, mas já tive que alugar outra máquina. A gente aluga quando tem muita coisa pra fazer, mas vale mais a pena comprar a máquina porque a gente paga $\mathrm{R} \$ 120,00$ por mês de aluguel.

Embora dona Jacira diga que ainda não parou durante o primeiro semestre do ano - já que nossa conversa se deu em junho de 2010 - sua fala permite entrever períodos de pico na produção, quando ela aluga máquinas adicionas. E, sobre a necessidade de variação dos modelos e dos materiais empregados de acordo com a sazonalidade da feira da sulanca e dos movimentos de sacoleiros, é Diano quem nos revela suas estratégias: 
Aqui é jeans. Quer dizer, o forte mesmo é jeans, mas a gente tem que trabalhar com outras coisas. Que só o jeans não dá. Agora, por exemplo, tá na época do São João, então o xadrez tá saindo muito. Tá na moda né? A gente tem que tentar tudo, o jeans tá fraco, usa o xadrez, o $\mathrm{PT}^{5}$. Tem que ter versatilidade. Uma bermuda xadrez sai daqui a $\mathrm{R} \$ 9,00$ e vende na feira a $\mathrm{R} \$ 10,00$. Tem tempo fraco e tempo bom. No início do ano, por exemplo, é tempo fraco. Tem o carnaval, carnaval é tempo fraco de feira. Do carnaval até o São João é fraco. Aí, no São João melhora e no fim do ano, no natal, também, né? (Diano, ênfases minhas).

Em um contexto de incerteza e intermitência dos recursos materiais disponíveis, a versatilidade é um antídoto fundamental de que os sulanqueiros lançam mão para driblar as dificuldades financeiras que se interponham diante deles. Eis aí a importância do ser desenrolado ${ }^{6}$, que constitui uma habilidade característica do sulanqueiro (pré-requisito mesmo para se adaptar neste meio economicamente mutável). Esta sazonalidade do movimento da feira, que incide sobre o ritmo e as relações de produção, relaciona-se também com variações nas “configurações sociais” (Elias, 1994) com as quais o observador se depara no bairro do Salgado - isto é, variações na maneira como as pessoas e as famílias se ligam entre si, em relações de dependência recíproca, perpassadas por assimetrias de acesso ao poder, conforme o caráter dinâmico do modelo figuracional eliasiano. Temporalidades, territorialidades e dinâmicas sociais se encontram intrinsecamente relacionadas. A versatilidade profissional evocada por Diano como um meio possível de contornar o tempo fraco da feira engendra também uma dinâmica social na medida em que diferentes objetos (o tecido xadrez, o PT) - mas também diferentes ofícios que são ativados paralelamente à produção e comercialização de vestuário, os quais também conferem parte do significado do termo versatilidade, no contexto local - fazem a mediação entre atores sociais também diversos. Além disso, no tempo das vacas gordas, os próprios fabricos familiares têm sua organização alterada pela entrada de novos atores costureiros, no contexto das relações de produção ali estabelecidas. Dona Judite, sulanqueira e lojista do Polo Comercial de Caruaru, me

\footnotetext{
${ }^{5}$ PT: pano para tingimento.

${ }^{6}$ Esta categoria do ser desenrolado é sintetizada na seguinte fala de William, amigo de Diano: "Pro sulanqueiro e pros feirantes não precisa de profissionalização não. Tem que ser desenrolado. Se for desenrolado, aprende a costurar, aprende a vender. O povo aqui é especialista em não ser especialista. É especialista em ganhar dinheiro. Curso de especialização é desnecessário. Aqui o pessoal é administrador na prática. O Diano que você conheceu, por exemplo. Com 15 anos ele já tinha comprado um Chevette. Depois ele comprou um Fiat Uno 2002, depois um Estrada, depois um Celta. Hoje ele tem uma F250, mas ele tava antes com uma Hiloux, que é o símbolo do sulanqueiro. O povo aqui vai comprando pra manter o dinheiro dentro da família. Por isso é que todo mundo quer trabalhar pra família, não quer trabalhar pros outros".
} 
disse o seguinte a este respeito: "Eu mesma que costuro junto com o meu marido, mas quando o movimento tá melhor a gente contrata uma ou duas costureiras. O meu marido corta e eu costuro mais" (grifo meu). Vê-se que aquele princípio de trabalhar com a família em detrimento dos de fora pode - no tempo bom da feira - ser relativizado. Mesmo os limites da família se encontram, portanto, em constante reordenação e constituem matéria de negociação conforme salienta Ana Claudia Marques (2002) acerca de regiões próximas do Sertão de Pernambuco. A noção de “configuração social”, formulada por Norbert Elias, por seu caráter provisório que o distingue da noção de "estados sociais" (que o autor atribui ao estrutural-funcionalismo de Talcott Parsons) é, pois, muito útil aqui. Às temporalidades específicas da sulanca correspondem tanto territorialidades específicas quanto configurações sociais dinâmicas e em constante reordenação. Estes intermináveis e intermitentes processos de deformação e reconformação dos grupos podem ser observados tanto em pequena escala, como no caso do fabrico de dona Judite, quanto no nível municipal e regional, já que aquela população flutuante mencionada na introdução é potencializada em alguns períodos do ano, como o natal, mas, sobretudo, no período da festa de São João, $o$ melhor mês do ano:

Você perdeu o melhor mês do ano, que foi Junho, quando tem a festa de São João. Aí que tu ia ver o formigueiro de gente que ia tá aqui. É gente de todos os cantos do país. Eu acho até que de todo o mundo! É argentino, espanhol... (vendedor de churrasquinho que trabalha em frente ao parque de eventos Luiz Gonzaga, onde ocorre a festa de São João).

Não sei, entretanto, até que ponto esta noção de junho como o melhor mês do ano constitui opinião generalizada, nem se outros municípios vizinhos compartilham este ponto de vista - uma vez que a festa de São João de Caruaru é a maior da região e rivaliza com Campina Grande, na disputa pelo título de maior São João do Mundo. As regularidades que pude identificar dizem respeito à alternância de períodos bons e períodos fracos da feira da sulanca. Em Santa Cruz do Capibaribe, por exemplo, pelo menos um de meus interlocutores (quando se referia às consequências da transferência da feira da sulanca para o Santa Cruz Moda Center, antes realizada no centro da cidade) destacou antes o fim do ano do que o período do São João, como a melhor época.

No centro era quase a mesma coisa pra mim, visse? Os dormitórios eram dentro da feira, isso mudou, mas era quase igual. Não mudou muito pra mim não. Tem semana que dá mais movimento, tem semana que dá menos. É a época mais fraca e a época 
mais forte. São João melhora, mas fim de ano é melhor. (Seu Pedro, sulanqueiro que trabalha no Santa Cruz Moda Center, grifo meu).

Não obstante, independentemente de quais meses marquem os períodos fortes e fracos das vendas e, por conseguinte, também da produção dos sulanqueiros, o fato é que os depoimentos que pude recolher a respeito deste universo profissional tendem a se organizar a partir deste esquema de alternâncias entre tempo bom e tempo ruim. Mais do que isso ainda, não apenas os relatos sobre o trabalho na sulanca apresentam esta cronologia que oscila entre o tempo das vacas magras e o tempo das vacas gordas, senão também algumas narrativas biográficas que registrei são organizadas a partir do mesmo modelo. O que chamei aqui de "ciclos da sulanca" parece recapitular todo um esquema narrativo que orienta também a construção discursiva das memórias de meus interlocutores nas quais aparecem experiências de sofrimento e escassez de recursos materiais decorrentes da seca. Vejamos este relato de seu José Mário referido ao período no qual ele foi soldado do exército, quando sua condição financeira melhorou comparativamente à fase precedente. Esta fase boa de sua juventude é narrada em meio a dois períodos ruins:

Com 17 anos eu aumentei a minha idade pra entrar no quartel do exército. Porque era a única opção. Nessa época, a seca era uma tristeza. Não tinha trabalho em Caruaru. Era só o povo indo-se embora pra São Paulo e pro Rio de Janeiro, pra São Paulo e pro Rio de Janeiro. E quem não tinha condições de ir pra lugar nenhum ficava sofrendo, perdido aqui, né? Então eu aumentei a idade pra fazer os exames no quartel. Fiz os exames pro quartel e fui aprovado em todos os testes, mas fiquei no excesso de contingente - que é quando eles querem, por exemplo, só 200 homens e têm 400 querendo entrar. Então eu dei um jeito de ir pra Garanhuns. Peguei um ônibus aqui, um carro acolá e cheguei em Garanhuns. Eu tinha o dinheiro pra ir, mas não tinha dinheiro pra tomar um café. Quando eu cheguei lá os oficiais ainda estavam tomando o café da manhã, eu fui o primeiro a chegar. E quando um deles abriu a porta e me viu lá perguntou-me o que é que eu estava fazendo lá. E eu disse que tinha vindo de Caruaru sem tomar café pra lá pra entrar no quartel. O oficial virou-se então pra mim e disse: 'aqui não é lugar de dar vida a ninguém não, aqui a gente ensina a tirar a vida, mas você me pegou num dia santo'. Então ele me levou pra dentro do quartel, me deu café e disse: 'olhe aqui, vá praquele alojamento ali e fique lá que amanhã eu lhe procuro'. Então eu fui pro alojamento e, naquela noite, ia ter um 'rebú' - que é o nome que eles dão a uma missão surpresa, no quartel. Aí o sargento passou distribuindo as fardas pros soldados e me deu uma também. Eu então peguei a farda e vesti. Cabia três pessoas dentro da farda, mas eu vesti mesmo assim. Aí foi aquela coisa, marcha pra cá, flexão pra lá, e corre, e entra 
no rio. Aí, quando foi no outro dia, o oficial chegou lá e me viu fardado e perguntou: 'o que é que você está fazendo aqui?' E eu respondi: 'me mandaram vir pra cá e eu vim, me mandaram vestir esta farda e eu vesti'. E ele disse: 'até que você tem jeito!' E aí eu fiquei. Passou uns três meses e eles me registraram. Mas aí foi aquela coisa: O Cabra acostumado a viver na necessidade, na nudez, na fome, na seca, essa coisa toda, que quando ganha dinheiro quer meter o pau, né? Então eu queria comprar sapatos, comprar nas camisarias de bacana - que hoje em dia não existem mais comprar comida. Comia coisa que nem sabia o que era. Só queria saber se era caro. Mas, depois de um tempo, teve um oficial que pegou bronca comigo porque ele me fez uma pergunta e eu respondi. Ele virou-se pra mim e disse: 'soldado, o que é que você acha do Brasil?’ Aí eu disse: 'O Brasil nação ou o Brasil exército? E ele disse: 'Fale aí qual é a diferença?' E eu lhe disse: 'O Brasil nação, eu não conheço outra terra então eu tenho que amar. Não conheço outra pra saber se é melhor ou pior então eu gosto desta. O Brasil quartel é muita humilhação e pouca liberdade'. Então o oficial zangou-se comigo e a partir dali ele veio em cima de mim. Até que chegou um dia em que outro oficial virou-se pra mim e disse: "você tem três opções ô Oliveira: ou você pede demissão, ou você é demitido, ou você vai ser transferido lá pra Amazônia, que é a única vaga que eu tenho'. Então eu disse: 'deixe que eu peço demissão'. E aí, quando eu volto pra Caruaru, cadê que tinha trabalho? Parecia que a cidade tinha parado no tempo. Era a mesma necessidade que eu tinha deixado antes de ir pro quartel. (ênfases minhas)

A migração de toda a família de seu José Mário para São Paulo também apresenta o caráter de uma estratégia provisória. Dona Eugênia nos apresenta, no excerto abaixo, esta fase como um tempo bom economicamente que se interpõe a dois períodos que poderíamos aproximar do tempo das vacas magras - o pré-migração e o pós-migração de retorno.

Aí, nessa época, o irmão de Zezinho, que também trabalhava com mármore lá em São Paulo, veio passar uns tempos aqui. E viu a situação e disse: 'Ô Zezinho, você tá perdendo tempo aqui, fazendo uma pedrinha ou outra. Vamos-se embora pra São Paulo comigo que você vai ganhar dinheiro" (...) "E esse tempo todo que a gente passou em São Paulo a gente ganhou dinheiro, visse? Zezinho trabalhando na marmoraria mais os irmãos dele e eu vendendo minhas costuras, meus artesanatos. Eu já tinha os lugares certos pra entrar e era tanta gente que queria comprar pra revender que eu passava em frente as lojas escondida porque não dava conta de costurar tanta coisa. Mas o tempo todo que a gente passou em São Paulo eu só pensava em voltar pra Caruaru mais meus filhos e Zezinho. Foram onze meses que eu pensava todos os dias em voltar. E toda compra que eu fazia eu comprava a mais que era pra ter uma feira boa quando eu voltasse. Porque eu sabia que a coisa pra essas bandas daqui não tava nada fácil não. Se eu fosse comprar um quilo de arroz 
eu comprava dois e guardava um, se fosse comprar cinco quilos de açúcar - que lá em São Paulo eles vendem aqueles pacotes de cinco quilos fechado - eu comprava um saco a mais. E passava naquelas fabricas de tecido e achava os retalhos barato e comprava, já pensando em trazer pra costurar aqui, porque eu só pensava em voltar. Quando eu voltei eu vim com meio caminhão de retalho que eu comprei lá. E vim com uma feira muito grande de lá também. Só foi-se acabando rápido porque a gente dava um quilo de arroz pra um parente, um quilo de feijão pra outro. Então não durou muito.

Tudo se passa como se a experiência da seca, fenômeno também intermitente (ao que se adicionam frequentemente estratégias econômicas igualmente provisórias, como foi o caso da entrada de seu José Mário no exército, embora, neste caso específico, seu desligamento tenha se dado à revelia de sua vontade), conferisse, de um lado, um habitus e, de outro, esquemas interpretativos que habilitam meus interlocutores a se mover com certa plasticidade sobre um terreno econômico instável. Experiências biográficas marcadas por alternâncias drásticas parecem assim levar à elaboração da autobiografia em termos cíclicos, de bonança e escassez intercaladas. Nesse sentido, as condições naturais do agreste pernambucano e as características do trabalho informal na feira da sulanca, compartilham pelo menos uma propriedade - qual seja, a incerteza econômica que acarretam. Este esquema de alternância entre tempos bons e tempos ruins orienta tanto a construção discursiva das memórias de parte dos sulanqueiros (e também de outros trabalhadores da região - tais como os artesãos do barro cujo ritmo do trabalho também acompanha o tempo das vacas magras e o tempo das vacas gordas), quanto os modos peculiares de temporalização do ciclo da sulanca. Neste último caso, como vimos, a escala reduz-se a um calendário anual de eventos importantes (tanto locais - festa de São João -, quanto nacionais - natal, dia das mães, etc.) que incidem sobre o movimento dos sacoleiros que chegam à feira da sulanca e, portanto, sobre a produção e comercialização de seus produtos. A esta escala anual as formulações de meus interlocutores adicionam uma segunda escala de temporalização, que passo agora a apresentar.

\section{Sulanca é um processo muito graúdo: segundo nível de temporalização.}

Mercadoria da sulanca chega todo dia. O trabalho aumenta mesmo é de quintafeira até sábado. Sábado a peça já tem que estar pronta pra ir pra lavanderia. Às vezes, na sexta, a gente já tá entregando a mercadoria. Porque aí vai pra lavanderia pra depois colocar botão, limpar, ensacar e levar pra feira, na terça-feira. Sulanca 
é um processo muito graúdo. Quando a peça chega pronta na loja já rodou uns quinze dias pelas facções e lavanderias. A peça leva de sete a quinze dias pra ficar pronta. É estilo cooperativa, né? Tem algumas fábricas que fazem tudo, feito essa dai (apontando para uma fábrica localizada do outro lado da rua, quase diante de sua residência). Mas, no sistema de facção é assim. Às vezes, tem facção de corte. Lá o sujeito risca e corta o tecido. Aí, já cortado, vai pra facção de costura, normalmente é uma casa só. Daí vai pro acabamento - que é o que eu faço. Daí vai pra lavanderia, depois prega botão, outro acabamento, ensaca e leva pra feira. Tem época que o cliente muda a mercadoria; traz cueca pra fazer o acabamento. $O$ modelo da peça depende da estação né? Do que tá vendendo na época. (José Sinovaldo).

A descrição de Sinovaldo fornece uma imagem interessante do que me parece ser um segundo nível de temporalização dos ciclos da sulanca. Esta outra escala se interpõe ao primeiro nível acima caracterizado, ambos se condicionando reciprocamente. Assim é que este processo muito graúdo tende a ser compreendido por um período que oscila entre uma semana e quinze dias, precisamente de acordo com o primeiro nível. Sendo a periodicidade da feira da sulanca semanal (às terças-feiras), conforme seja o tempo das vacas magras ou das vacas gordas, o ciclo de produção das mercadorias que deverão abastecer a feira faz-se mais ou menos elástico, respectivamente. É que, no primeiro caso, tende a sobrar, ao cabo da feira, um volume residual de mercadorias que deverá completar o montante de peças da feira seguinte, na próxima terça-feira. Entrementes a mercadoria pode circular mais vagarosamente entre as casas dos faccionistas ou produtores por conta própria, diminuindo o ritmo do trabalho. No tempo das vacas gordas, entretanto, a produção deve chegar a seu estado acabado todas as segundas-feiras porquanto certamente serão esgotadas no dia seguinte, iniciando-se assim, no mesmo dia, o ciclo da próxima feira.

A narração do ciclo temporal de produção da sulanca, feita por José Sinovaldo e registrada na abertura desta sessão, já se acompanha de uma descrição do espaço percorrido pelo material de trabalho. Este segundo nível de temporalidade relaciona-se, pois, com a maneira pela qual circulam pessoas e objetos, pelos bairros de sulanqueiros, especificamente, e pela cidade e região (uma vez que muitos sulanqueiros vendem suas peças nas demais feiras da sulanca, em Santa Cruz do Capibaribe e Toritama, por exemplo), em geral. Nesse sentido, o ciclo da sulanca pode ajudar-nos a pensar sobre a "biografia cultural das coisas" (Kopytoff, 1986) nestes locais. Biografia esta que inclui 
uma fase como serviço (isto é, o material de trabalho) que transita inicialmente por algumas casas contíguas do bairro que constituem, por assim dizer, uma linha de produção. Quando o material deixa o bairro do Salgado em direção às feiras da sulanca (das diversas cidades da região), ou ao Centro Comercial de Caruaru (uma espécie de Shopping Center do vestuário), ele entra em outra fase de sua biografia cultural, agora como mercadoria. Sua mobilidade geográfica cresce em escala, a qual tende a se ampliar regional, transregional, transnacional e, por vezes, transcontinentalmente de acordo com o destino que cada sacoleiro lhe dará.

Para que estas diversas localidades adquiram as mercadorias da sulanca importa que os sulanqueiros saibam conquistar uma demanda que é própria das grandes logomarcas de vestuário. O processo criativo da modinha, frequentemente a cargo das mulheres, constitui a estratégia por meio da qual os sulanqueiros apropriam-se desta demanda. O termo modinha refere-se aos modelos de roupas que estão na moda e que são identificados, sobretudo nas personagens das telenovelas. A televisão constitui aqui o espaço fornecedor de informações fundamentais sobre o campo da moda para o mundo da sulanca. Um exemplo a este respeito que escutei mais de uma vez parece ser paradigmático entre meus informantes, por sua incrível recorrência. Trata-se de um modelo de calça jeans que passou a ser muito cobiçado pelas mulheres, depois que uma personagem de telenovela apareceu vestida com ele. "Uma semana depois de o modelo aparecer na televisão, na feira seguinte," - comentam meus interlocutores - "ele já estava sendo vendido pela maioria dos feirantes". Encontramos também aqui aquela segunda escala de temporalização do trabalho da sulanca já que, "na semana seguinte" as roupas das telenovelas já figuram como produtos da feira. A programação da televisão que constitui, na maioria das vezes, uma espécie de "fast-food cultural" (Bourdieu, 1997 :41) parece sofrer, portanto, pela ação das sulanqueiras modelistas da modinha, uma reativação por meio da qual são acessadas informações fundamentais para a conquista da demanda, no menor tempo possível (já que os valores e padrões da moda são também bastante instáveis).

O caráter de urgência que caracteriza a modelagem e produção de vestuário entre os sulanqueiros parece constituir também parte de uma estratégia de disputa pelos clientes sacoleiros, sempre a procura de novidades, como se diz em Caruaru. Aqui, além do trabalho criativo das modelistas da modinha, inspirado nas roupas da televisão, testemunhamos também a reprodução do modelo que está vendendo na época. 
Depende muito da época, se a época tá forte ou se tá fraca. É questão de acertar o modelo. O modelo que tá vendendo mais na época. É sempre assim, os modelos das peças, um sulanqueiro imita o outro que imita o outro, e assim vai. Se der certo, vende; se não der, muda o modelo. É igual a estas bermudas xadrez aqui. Você tá na feira aí você vê que tá vendendo. Todo mundo começa a falar: 'tá vendendo, xadrez tá vendendo muito', 'tá vendendo, tá vendendo'. O pessoal fala que tá vendendo. Aí vai na feira, compra um modelo, leva pro estilista e ele desmancha aquele modelo. Ele corta a modelagem. A gente paga, pra fazer isso, $\mathrm{R} \$ 60,00$ a $\mathrm{R} \$ 70,00$ pro estilista. Aí pega a modelagem e é só cortar. (Diano).

É também, de certa forma, o regime de urgência na produção, decorrente da periodicidade semanal da feira da sulanca, o aspecto que condiciona a ordenação espacial e a distribuição social do trabalho nos bairros majoritariamente habitados por sulanqueiros. Tempo, espaço e relações sociais de produção encontram-se intrinsecamente relacionados, no mundo da sulanca.

\section{Territorialidades da costura de vestuário em Caruaru-PE.}

Quando, no dia 15 de julho de 2011, eu conversava com uma mulher proprietária de um bar, no bairro do Salgado, testemunhei duas crianças que desciam um morro diante de nós carregando pilhas de peças de vestuário semi-confeccionadas, tendo entrado, por fim, em outra casa e retornado, após alguns minutos, de mãos vazias. Ao descer o morro do bairro no qual se localizava o bar de minha interlocutora, vi também um homem carregando pilhas de peças de jeans que saiam de uma oficina que mais parecia um local de estofamento de carros - o que, com efeito, eu confirmaria algumas semanas mais tarde, quando visitei este recinto e descobri que se tratava de duas oficinas em uma, de peças de vestuário e de estofamento (a máquina de corte sendo, neste caso, a mesma). $\mathrm{O}$ homem saía deste fabrico-oficina e conduzia as peças à casa vizinha. Este trânsito de pessoas e materiais de trabalho evoca uma das características mais importantes do universo social dos sulanqueiros - a saber, a distribuição familiar e pela vizinhança do trabalho na costura, por assim dizer, múltiplas linhas de montagem distribuídas pelo bairro. Testemunhamos aqui uma especialização produtiva dos bairros habitados pelos trabalhadores da sulanca. Seu José Mário, com sua profunda sensibilidade etnográfica, certa feita apresentou-me uma descrição bastante interessante desta especialização produtiva, no caso do bairro onde ele reside, o Salgado: 
Veja você que este bairro aí da frente [apontando para a área residencial diante de nós compreendida pelo Salgado] é o mais populoso de Caruaru. Tem 80 mil habitantes! A cada dez casas, oito são fabricos. Veja você, Toritama tem 23 mil habitantes, Santa Cruz do Capibaribe tem 70 mil habitantes... [Nesse momento, meu interlocutor enumerou uma série de cidades contíguas, com suas respectivas cifras populacionais, que sou incapaz de reproduzir]. Então veja, só o barro do Salgado tem uma população maior que todas estas cidades e de algumas delas somadas entre si. E em dez casas, oito são fabricos. Só de lavanderia de jeans tem umas duzentas. Então o bairro do Salgado economicamente é o mais forte de Caruaru. É o que segura Caruaru e a feira da Sulanca. Se um candidato a prefeito criar problemas aqui ele perde as eleições. Aqui dentro (no bairro do Salgado) você tem lavanderias, fabricos e facções, que são coisas diferentes. Tem o cabra que trabalha na lavanderia, o dono do fabrico e os costureiros dos fabricos e têm os costureiros de facção, que trabalham em casa pros dono do fabrico. Tem facção que a pessoa trabalha em casa e o dono só pega e vende, só põe a mão na grana. Então tem estas três coisas diferentes pra você pesquisar - os fabricos, as lavanderias e as facções.

As relações entre tempo e espaço constituem também um centro de interesse desta comunicação na medida em que tal especialização produtiva é condicionada pelos modos nativos de periodização do ciclo da sulanca. As duas escalas de temporalidades apresentadas acima podem ajudar-nos a direcionar a atenção para uma infinidade de variações e especializações locais que o trabalho na costura de vestuário assume de acordo com sua distribuição pelos diferentes bairros de Caruaru, bem como conforme os vários arranjos produtivos encontrados - fabricos, confecções, facções, lavanderias, unidades domésticas de produção, grandes fábricas de vestuário, etc. Assim é que, por exemplo, no bairro Boa Vista, nos deparamos com uma determinada organização da produção de vestuário especializada em peças de malha, ao passo que, no bairro do Salgado, a produção concentra-se sobre peças de jeans. Um dos pressupostos deste trabalho - inspirado na bibliografia antropológica ligada ao projeto Porto Rico (por exemplo, em Wolf, 2003) - é que as variações no aspecto propriamente técnico do processo produtivo (entre a produção de peças de malha e de jeans, por exemplo) fazem-se acompanhar de diferenças nos aspectos socioculturais dos costureiros e costureiras, como de resto, dos demais trabalhadores destas localidades.

O bairro do Salgado é a este respeito um caso exemplar. As peças de vestuário confeccionadas com jeans carecem de processos de acabamento que as peças de malha prescindem inteiramente; estas técnicas de ofício características do jeans requerem uma 
infraestrutura também específica, do que as lavanderias constituem o exemplo mais evidente, mas também as oficinas mecânicas, lojas de peças de máquinas, etc. A lavagem do jeans, por sinal, impõe um regime de urgência na produção maior no Salgado do que em Boa Vista, já que as peças de malha majoritariamente produzidas neste último bairro prescindem desta etapa. O processo produtivo das roupas de malha é, pois, mais simples e rápido. As pré-condições materiais da produção em jeans conferem uma organização social peculiar ao bairro do Salgado, distinguindo-o do bairro de Boa Vista. Vista sob esta perspectiva das especificidades do jeans fica mais fácil compreender como a especialização do bairro do Salgado decorre também das temporalidades específicas do ciclo da sulanca ditadas pela periodicidade da feira e pela sazonalidade que marca o movimento dos sacoleiros. A contiguidade entre os segmentos desta linha de montagem constituída pelo bairro é uma imposição do segundo nível de temporalização, sobretudo no tempo das vacas gordas. Por exemplo, quando uma máquina de costura quebra, em pleno mês de junho (período de apogeu das vendas em decorrência da festa de São João), é fundamental que haja um mecânico disponível no bairro em fração de minutos. Importa, pois, que o mecânico seja também vizinho.

\footnotetext{
O tempo é todo contado porque a feira é só um dia da semana né. Se der problema na máquina o mecânico tem que vir rapidinho. Por isso que é vantagem a gente ter tudo aqui pertinho. No Salgado tem de tudo. Tem mecânico, loja de peças, tem de tudo. O mecânico vem em casa, não precisa levar lá. O Salgado é uma cidade dentro de Caruaru. (Diano)
}

A caracterização do bairro do Salgado como "uma cidade dentro de Caruaru" nos chama a atenção para a positividade da circulação de pessoas e objetos pelo bairro. Trata-se de salientar o fato de que a passagem destes materiais pelas mãos de diferentes parentes e vizinhos converte-os em membros de uma mesma corporação profissional. Condição que por vezes se sobrepõe a outras formas de relações entre estes sujeitos - tal como o pertencimento a uma mesma instituição religiosa. A distribuição social do trabalho pela vizinhança constitui, por conseguinte, um caso privilegiado para a observação de outros aspectos destas "relações multiplex", que incluem parentesco, família, vizinhança, amizade, afinidade, por vezes, religião e, evidentemente, trabalho. A relação entre o segundo nível de temporalidade da sulanca e sua circulação pelas casas de parentes e vizinhos, no bairro do Salgado, pode ser depreendida a partir de uma 
descrição do processo produtivo levado a curso por Diano, junto com sua família e vizinhos:

Aqui na garagem eu mesmo corto o tecido e depois mando para as costureiras de facção. Tudo vizinho aqui do bairro mesmo. São duas facções com 3, 4 costureiras, cada uma. Isso dependendo da época. Então eu trabalho com uma média de oito costureiras. Por jaqueta eu pago $\mathrm{R} \$ 2,20$ às costureiras. Depois de montada, a mercadoria volta pra cá. Aqui eu mesmo faço o coz, faço a riata (tira estreita de jeans, ou outro tecido, empregada para fazer o passador e o cadarço de uma calça). Aí depois, meu irmão Enrique (com 12 anos de idade), faz o caseado. Eu pago $\mathrm{R} \$ 00,03$ a ele por cada peça que ele faz. Até ficar pronta uma peça passa pela mão de umas 8 pessoas e por umas cinco, seis casas do Salgado. Depois do caseado vem a lavanderia, as peças vão pra casa da minha tia, que mora lá do outro lado daquela rua [apontando para uma rua contígua à sua]. Ela tem um fabrico maior, com muitos funcionários, costureiros, costureiras. E ela tem lavanderia lá. Então eu lavo as minhas peças lá porque ela me dá desconto também. Todo descontinho, em cada etapa, que você consegue faz diferença na hora de vender. Se eu fosse pagar lavanderia pra um estranho, eu ia pagar $\mathrm{R} \$ 1,70, \mathrm{R} \$ 1,80$ por peça lavada. Como eu faço com ela eu pago $\mathrm{R} \$ 1,40$. E ela também faz esse bordado aqui ó [mostra-me o bordado nas costas de uma jaqueta], eu pago, em média, $\mathrm{R} \$ 1,00$ por peça bordada. Umas peças o bordado é $\mathrm{R} \$ 1,10$, outras é $\mathrm{R} \$ 00,90$, outras é $\mathrm{R} \$ 00,80$, outras $\mathrm{R} \$ 1,20$, depende de quantas cores tem o desenho. Se eu fizesse fora também ia pagar mais caro que isso. Pra mercadoria, $\mathrm{R} \$ 00,10$ que você ganha por etapa é tudo; $\mathrm{R} \$ 00,10$ na limpeza, $\mathrm{R} \$ 00,10$ na lavanderia, $\mathrm{R} \$ 00,10$ no bordado, $\mathrm{R} \$ 00,10$ no caseado e no produto final você pode botar um real mais barato. Depois disso a peça volta pra cá pra fazer a limpeza e pregar botão. (Diano).

A especialização dos bairros constitui, pois, uma condição de possibilidade para uma boa logística ${ }^{7}$ dos fabricos, que precisam funcionar em um período exíguo de sete dias. Em segundo lugar, um deslocamento do material por grandes distâncias, entre as casas que compõem as etapas do processo produtivo, incluiria um volume maior de combustível para o transporte e significaria por isso um encarecimento da mercadoria, o que poderia ser fatal em um contexto de competição pelo preço, segundo a expressão empregada regularmente por meus interlocutores para se referir a outra característica da feira da sulanca. De modo similar, o transporte da mercadoria entre os bairros de sulanqueiros e a feira é outro aspecto que deve ser considerado tanto pelos trabalhadores, em suas atividades profissionais, quanto pelo observador, em seu relato

\footnotetext{
${ }^{7}$ Isto é, para um funcionamento eficiente da distribuição familiar (e pela vizinhança) do trabalho entre as casas do bairro. O termo logística, neste contexto, foi empregado por Diano.
} 
deste universo. Uma eventual mudança no dia de realização da feira da sulanca (como a ocorrida em 2011, por exemplo, quando ela passou a realizar-se na madrugada de domingo) tende a ser recebida pelos feirantes como uma desorganização de seu modo de vida, de suas formas peculiares de estruturar e temporalizar o trabalho na produção e na feira. Dona Eugênia foi uma das primeiras pessoas a testemunhar este fato para mim:

A feira tinha mudado para domingo. Mas o povo não gostou não. Porque no domingo era aquela correria pra terminar e transportar a mercadoria. E o povo reclamava muito, visse? Então a feira voltou pra terça. (Dona Eugênia).

A especialização produtiva dos bairros seria, por assim dizer, o correspondente sociológico deste segundo nível de temporalização que constitui uma unidade de periodização do trabalho, na produção de vestuário, a qual se encerra com sua comercialização na feira da sulanca, ao cabo do que se inicia novo ciclo no processo produtivo. Esta unidade compreende, como registrado, um período de 7 a 15 dias, segundo seja o tempo das vacas gordas ou das vacas magras, respectivamente. Neste período de tempo se dá, portanto, o processo completo de produção e comercialização das roupas da sulanca. Esta escala temporal tem incidência direta sobre o processo produtivo porque seu ritmo é ditado, dentre outras variáveis, pela periodicidade da feira - o que imprime um caráter de urgência na produção somente amenizado pelo tempo das vacas magras.

\section{Considerações finais.}

Richard Sennet (2005) concentrando-se sobre o que denomina as "consequências pessoais do trabalho no novo capitalismo" destaca, dentre elas, a noção de "deriva", a dificuldade de construir um projeto de vida com uma direção definida e uma experiência biográfica "ilegível", do ponto de vista do trabalhador. Neste trabalho tentei basear minha construção analítica da categoria "ciclos da sulanca" nas formulações de meus interlocutores relacionadas às suas formas particulares de temporalizar seu trabalho; as quais se acompanham de modos igualmente peculiares de se mover no espaço público profissional e de planejar suas atividades. Particularmente o que meus amigos chamam de tempo das vacas magras e tempo das vacas gordas diz respeito à incerteza econômica ligada a seu trabalho contemporâneo, mas que recapitula a incerteza decorrente dos problemas históricos decorrentes da seca. As tradições locais e, sobretudo, as pragmáticas e os habitus incorporados nas ações práticas dos 
trabalhadores fundamentam certa adaptabilidade coletiva às condições de incerteza características de uma economia rural historicamente desenvolvida nesta região. Esta plasticidade que decorre das incertezas climáticas constitui a base para uma nova modulação de adaptabilidade. Desta vez às incertezas de ordem econômica decorrentes das dinâmicas do mundo da sulanca que, de certo modo, se assemelham e se sobrepõem ao novo capitalismo (que encontrou, pelas mesmas razões, um terreno fértil nesta região do agreste pernambucano). E, no entanto, isso não significa, neste caso, um novo modo de vida "ilegível" para os trabalhadores locais. Ao contrário, como vimos, a incerteza econômica é um dado presente nas narrativas biográficas de meus interlocutores; um dado central que as constitui, de certa forma, sendo, pois, parte de uma "legibilidade" característica. Se estes trabalhadores encontram-se em uma situação de "deriva", então eles desenvolveram, por assim dizer, técnicas de navegação específicas para estas condições.

\section{REFERÊNCIAS}

BOURDIEU, Pierre. Sobre a televisão. Rio de Janeiro : Jorge Zahar Ed, 1997.

BRENNER, Suzanne April. The domestication of desire: women, wealth, and modernity in Java. New Jersey: Princeton University press, 1998.

ELIAS, Norbert. O Processo Civilizador: uma história dos costumes. Volume 1. Rio de Janeiro: Jorge Zahar Ed, 1994.

INSTITUTO BRASILEIRO DE GEOGRFIA E ESTATÍSTICA. Cidades. Caruaru. Fonte: $\underline{\text { https://www.ibge.gov.br/cidades-e-estados/pe/caruaru.html }}$ (acesso em 05/03/2020).

KOPYTOFF, Igor. "The cultural biography of things: commoditization as process". In: APPADURAI, Arjun. The Social Life of Things: Commodities in Cultural Perspective. Cambridge: Cambridge University Press. pp. 64-91,1986.

MARQUES, Ana Claudia. Intrigas e Questões: vinganças de família e tramas sociais no sertão de Pernambuco. Rio de Janeiro: Relume Dumará: UFRJ, Núcleo de Antropologia da Política, 2002. 
SENNET, Richard. A corrosão do caráter: consequências pessoais do trabalho no novo capitalismo. Rio de Janeiro: Record, 2005.

UFPE. Estudo de Caracterização Econômica do Polo de Confecções do Agreste de Pernambuco. Recife: Relatório final apresentado ao SEBRAE-PE, 2003.

WOLF, Eric. Antropologia e poder. São Paulo: Editora UNICAMP, 2003.

Recebido 05/03/2020

Aprovado 10/04/2020 